\title{
ARTICLE OPEN Age-dependent effects of protein restriction on dopamine release
}

\author{
Fabien Naneix ${ }^{1,2}$, Kate Z. Peters ${ }^{3}$, Andrew M. J. Young ${ }^{1}$ and James E. McCutcheon $\mathbb{D}^{1,4}$
}

\begin{abstract}
Despite the essential role of protein intake for health and development, very little is known about the impact of protein restriction on neurobiological functions, especially at different stages of the lifespan. The dopamine system is a central actor in the integration of food-related processes and is influenced by physiological state and food-related signals. Moreover, it is highly sensitive to dietary effects during early life periods such as adolescence due to its late maturation. In the present study, we investigated the impact of protein restriction either during adolescence or adulthood on the function of the mesolimbic (nucleus accumbens) and nigrostriatal (dorsal striatum) dopamine pathways using fast-scan cyclic voltammetry in rat brain slices. In the nucleus accumbens, protein restriction in adults increased dopamine release in response to low and high frequency trains of stimulation $(1-20 \mathrm{~Hz})$. By contrast, protein restriction during adolescence decreased nucleus accumbens dopamine release. In the dorsal striatum, protein restriction at adulthood has no impact on dopamine release but the same diet during adolescence induced a frequency-dependent increase in stimulated dopamine release. Taken together, our results highlight the sensitivity of the different dopamine pathways to the effect of protein restriction, as well as their vulnerability to deleterious diet effects at different life stages.
\end{abstract}

Neuropsychopharmacology (2021) 46:394-403; https://doi.org/10.1038/s41386-020-0783-z

\section{INTRODUCTION}

The regulation of food intake in an ever-changing environment is a central survival process. Healthy diet requires a balanced intake of the three main macronutrients (carbohydrate, fat, and protein) [1]. Protein intake is especially important as amino acids are essential for many biological functions (growth and maintenance, synthesis of nucleic acids and hormones, immune response, and cellular repair) and many amino acids cannot be synthesized de novo. In humans, protein deficiency and a low protein diet are associated with muscle wasting, stunted growth, and increased vulnerability to infections, but may also, to some extent, contribute to obesity by generally increasing appetite [2-4]. Furthermore, protein deficiency and severe protein malnutrition are especially detrimental during development and early life when demand is highest [5-7]. Numerous species, including humans and rodents, regulate their food intake and food-related behaviors to avoid protein deficiency [8-13]. Increasing evidence implicates broad hypothalamic and limbic circuits in the regulation of protein appetite [10,13-15]. However, the impact of protein imbalance (high or low protein diet) on the function of these neurobiological circuits remains undescribed, especially when protein deficiency occurs during a critical period of early development.

The dopamine system plays a central role in food-seeking behaviors, food preference, and in the motivation to eat [16-19]. Recent data show that dopamine neurons integrate current physiological state (i.e., hunger and nutrient deficiency) to guide food-seeking behaviors [20-23]. Dopamine neurons are especially sensitive to the nutrient content of ingested food [24-28], through gut-to-brain axis [29, 30] and peripheral feeding hormones [31-35]. Furthermore, exposure to specific diets, such as high carbohydrate and/or high fat, impacts dopamine signaling within the nucleus accumbens (NAc) and the dorsal striatum [36-40]. However, the impact of low protein diet on the function of dopamine circuits is still largely unexplored.

Early life periods like childhood and adolescence are periods of particular vulnerability to the deleterious impact of various diets on corticolimbic circuits and reward-related processes [41-47]. Interestingly, the dopamine system undergoes delayed maturation taking place during adolescence making it vulnerable to external insults [47-54]. The impact of prolonged inadequate protein consumption on dopamine signaling remains unknown but may be exacerbated during adolescence when protein demand is increased to support rapid growth [55].

Here, we investigated the impact of protein restriction either during adolescence or adulthood on the function of the mesolimbic (NAC) and nigrostriatal (dorsal striatum) dopamine pathways using fast-scan cyclic voltammetry (FSCV) in rat brain slices. We found that protein restriction induced opposite effects on NAc dopamine release depending on age, with restriction increasing dopamine release in adults but decreasing it in adolescents. In the dorsal striatum, however, dopamine function following protein restriction was increased only in adolescents and not adults.

\section{MATERIAL AND METHODS}

Subjects

Male Sprague Dawley rats (Charles River Laboratories) were received either at weaning $(\sim P 21,50-70 \mathrm{~g})$ for adolescent groups

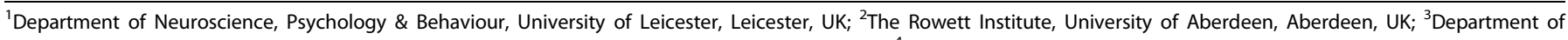

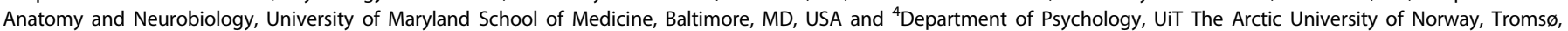
Norway

Correspondence: Fabien Naneix (fabien.naneix@abdn.ac.uk)

Received: 11 April 2020 Revised: 17 July 2020 Accepted: 21 July 2020

Published online: 31 July 2020 
$(n=13)$ or at adulthood (P60, 200-250 g) for adult groups $(n=$ 15). Rats were housed in groups of $2-3$ in individually ventilated cages $(46.2 \times 40.3 \times 40.4 \mathrm{~cm})$, in a temperature $\left(21 \pm 2{ }^{\circ} \mathrm{C}\right)$ and humidity (40-50\%) controlled environment with a $12 \mathrm{~h}$ light/dark cycle (lights on at 7:00 a.m.) and with food and water available ad libitum. All testing and tissue harvesting occurred in the light phase. Procedures were performed in accordance with the Animals (Scientific Procedures) Act 1986 and carried out under Project License PFACC16E2 granted by the UK Home Office after review from the local Animal and Welfare Ethical Review Board (AWERB) at the University of Leicester.

\section{Diets}

All rats were initially maintained on standard laboratory chow diet (Teklad global \#2918, Envigo) containing 18\% protein. One week after arrival rats either continued on standard laboratory chow diet (non-restricted group; Adolescents NR $n=6$, Adults NR $n=8$ ) or were switched to a modified AIN-93G diet containing $5 \%$ protein from casein (\#D15100602, Research Diets; proteinrestricted group: Adolescents PR $n=7$, Adults PR $n=7$; Supplementary Table 1) [11]. Rats had ad libitum access to their assigned diet. Protein restriction was maintained for 12-14 days either during adolescence (from P28 to P42) or during adulthood (>P70). Body weight and food intake data were collected daily throughout the experiments. Tissue was collected for voltammetry recordings immediately after this period (Fig. 1a).

\section{Slice preparation}

Rats were deeply anesthetized with chloral hydrate $(400 \mathrm{mg} / \mathrm{kg} \mathrm{i}$. p., Sigma-Aldrich), decapitated, and brains were removed and transferred to ice-cold artificial cerebrospinal fluid (aCSF) containing in mM: $126 \mathrm{NaCl}, 10$ glucose, $26 \mathrm{NaHCO}_{3}, 2.5 \mathrm{KCl}, 2.4 \mathrm{CaCl}_{2}, 2$ $\mathrm{MgCl}_{2}$, and $1.4 \mathrm{NaH}_{2} \mathrm{PO}_{4}$. Acute $300 \mu \mathrm{m}$ thick coronal slices, containing both the NAc and the dorsal striatum were prepared in ice-cold aCSF buffer using a vibratome (Leica VT1200S). Slices were kept at room temperature $\left(20-22^{\circ} \mathrm{C}\right)$ in aCSF saturated with $95 \% \mathrm{O}_{2}$ and $5 \% \mathrm{CO}_{2}$ for at least $1 \mathrm{~h}$ before the start of recordings.

\section{Fast-scan cyclic voltammetry recordings}

Unilateral slices were transferred to the recording chamber and superfused at $2 \mathrm{ml} / \mathrm{min}$ with aCSF saturated with $95 \% \mathrm{O}_{2}$ and $5 \%$ $\mathrm{CO}_{2}$ at $30^{\circ} \mathrm{C}$. Slices were allowed to equilibrate for $30 \mathrm{~min}$ prior to recordings. A twisted stainless steel bipolar stimulating electrode (MS303T/2-B/SPC, P1 Technologies) was placed at the surface of the slice within the NAc core or the dorsal striatum (Fig. 1b). A homemade glass capillary carbon-fiber microelectrode (tip length $50-100 \mu \mathrm{m})$ was positioned in the slice $\sim 100 \mu \mathrm{m}$ beneath the tissue surface and $100-200 \mu \mathrm{m}$ from the stimulating electrode $[56,57]$. For FSCV recordings, a triangular voltage waveform was applied ( -0.4 to $+1.3 \mathrm{~V}$ and back versus an $\mathrm{Ag} / \mathrm{AgCl}$ reference electrode; $400 \mathrm{~V} / \mathrm{s}$ ) using a custom-built headstage circuit (University of Washington Electronics and Materials Engineering Shop, Seattle, WA) and TarHeel voltammetry software (Chapel Hill, University of North Carolina [58]). The waveform was initially applied at $60 \mathrm{~Hz}$ for $10 \mathrm{~min}$, to condition the electrode outside of the tissue, and then applied at $10 \mathrm{~Hz}$ while all experiments were being conducted. Dopamine release was evoked by monopolar stimulation pulses $(0.7 \mathrm{~mA}, 0.2 \mathrm{~ms})$ [59]. Electrical stimulations were repeated at $3 \mathrm{~min}$ intervals to ensure consistent release. Stimuli were either single pulses (1 p) or trains of five pulses (5p) at frequencies ranging from 'tonic' $(1,5$, or $10 \mathrm{~Hz})$ to 'phasic' burst frequencies $(20 \mathrm{~Hz})$ of dopamine neurons reported ex vivo and in vivo [60-62]. Each stimulation was repeated three times in pseudo-random order and averaged to obtain the individual value for this frequency. Each slice yielded an individual recording site. The number of animals in each recording condition is $\geq 3$.

Extracellular dopamine levels ([DA $]_{0}$ ) were confirmed by examining current-voltage plots showing oxidation $(\sim+0.6 \mathrm{~V})$ and reduction $(\sim-0.2 \mathrm{~V})$ peaks using TarHeel software. Background (non-Faradaic) current was measured for $1 \mathrm{~s}$ between 4 and $5 \mathrm{~s}$ before the stimulation and subtracted from the signal. Dopamine currents (in $\mathrm{nA}$ ) were then converted to dopamine concentration (in $\mathrm{nM}$ ) using the calibration of each electrode against a known standard dopamine concentration. $[D A]_{0}$ peaks were measured following any stimulation artefacts as previously described [63]. As the electrical stimulations used varied in length and frequency, we also quantified DA release by using the area under the curve of $[D A]_{0}(A \cup C)$ calculated on a temporal window of $5 \mathrm{~s}$ (from +0.2 to $5.2 \mathrm{~s}$ after stimulation onset) in all conditions. Recording electrodes were calibrated after use using 1-2 $\mu \mathrm{M}$ dopamine solution in a flow cell system [64] and in the recording chamber.

\section{Statistical analysis}

Weight and food intake measures were analyzed using three- or two-way repeated measures ANOVAs with Diet (non-restricted NR, protein-restricted PR) and Age (Adults and Adolescents) as between factors and Day or Macronutrient (Protein, Carbohydrate, and Fat) as within factors. As rats were group-housed, food intake data were collected by cage, divided by the number of rats in the cage, normalized by kg of body weight and expressed as energy intake (kcal/kg of body weight). Energy intake was also analyzed as macronutrient breakdown.

For single pulse stimulation, $[D A]_{0}$ peaks, $[D A]_{0}$ AUC and clearance times ( $T_{80}$ : time for $80 \%$ decay from peak amplitude; $T_{20}$ : time for $20 \%$ decay from peak amplitude; half-life: time for $50 \%$ decay from peak amplitude) were analyzed using two-way ANOVAs with Age (Adults and Adolescents) and Diet (NR, PR) as between-subject factors. [DA] $]_{0}$ AUC in response to single pulses were plotted as cumulative probability and compared using Kolmogorov-Smirnov test. [DA] o peaks and AUC from frequencyresponse curves were analyzed using three-way and two-way repeated measures ANOVA using Age (Adults and Adolescents) and Diet (NR, PR) as between-subject factors and frequency (1, 5, 10 , and $20 \mathrm{~Hz}$ ) as within-subject factor. $5 \mathrm{p} / 1 \mathrm{p}[\mathrm{DA}]_{\mathrm{O}}$ ratios were calculated by dividing the average [DA] o peak value at $20 \mathrm{~Hz}$ by the average $[D A]_{0}$ peak value at $1 \mathrm{~Hz}$ for the same recording site, and were analyzed using two-way ANOVA with Age (Adults and Adolescents) and Diet (NR, PR) as between-subject factors. Sidak's and Dunnett's post hoc tests were performed when required.

Statistical analyses were conducted using GraphPad Prism 8. All values were expressed as mean \pm standard error of the mean (SEM). The alpha risk for the rejection of the null hypothesis was 0.05 .

Upon publication, all data analyzed in this paper will be available on Figshare (https://doi.org/10.25392/leicester.data. c.5008904).

\section{RESULTS}

Age-dependent impact of protein restriction on weight We first investigated the impact of protein restriction during either adolescence or adulthood on weight and weight gain (Fig. 1C). As we previously observed [11], protein restriction at adulthood did not significantly affect rats' weight (two-way repeated measures ANOVA: Diet, $F(1,13)=0.5, p=0.5$; Day, $F(11,143)=85.5, p<$ 0.001 ; Diet $\times$ Day, $F(11,143)=0.4, p=1.0)$. In contrast, protein restriction during adolescence significantly decreased weight gain, relative to control diet (Diet, $F(1,11)=19.8, p<0.001$; Day, $F(13$, $143)=478.7, p<0.001$; Diet $\times$ Day, $F(13,143)=234.0, p<0.001)$. Both NR and PR adult rats exhibited similar low weight gain ( $48 \pm$ $6 \mathrm{~g}$ and $40 \pm 6 \mathrm{~g}$, respectively). NR adolescent rats showed substantial weight increases $(+118 \pm 4 \mathrm{~g})$, indicating a normal developmental growth whereas PR rats showed only a modest increase in their weight $(+21 \pm 4 \mathrm{~g}$; two-way ANOVA: Diet, $F(1,24)=23.14, p<0.001$; Age, $F(1,24)=97.8, p<0.001$; Diet $\times$ 


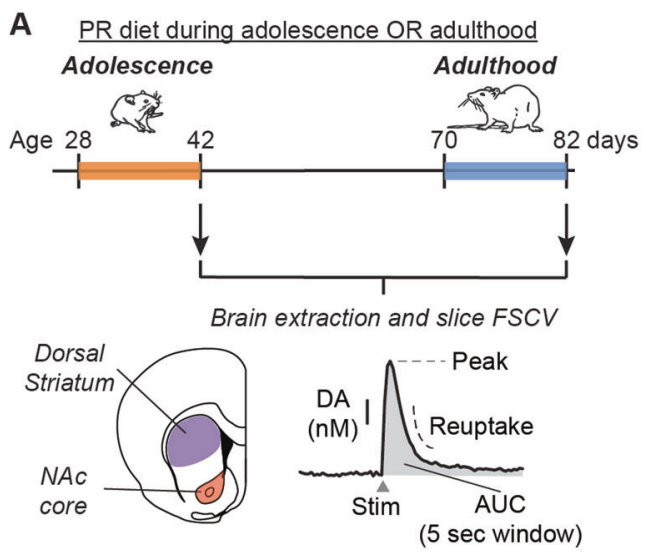

C
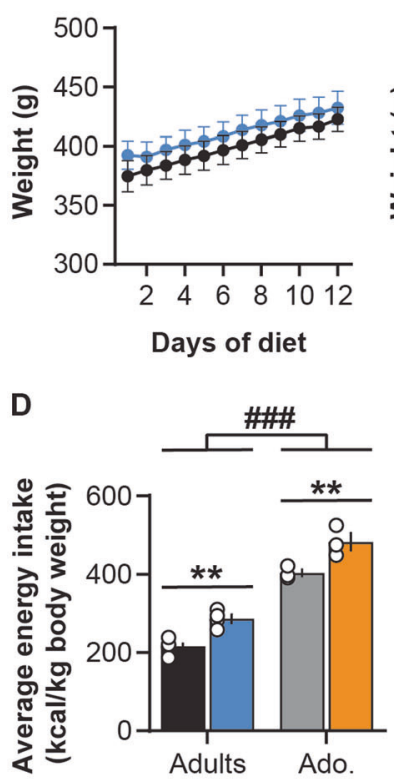

B

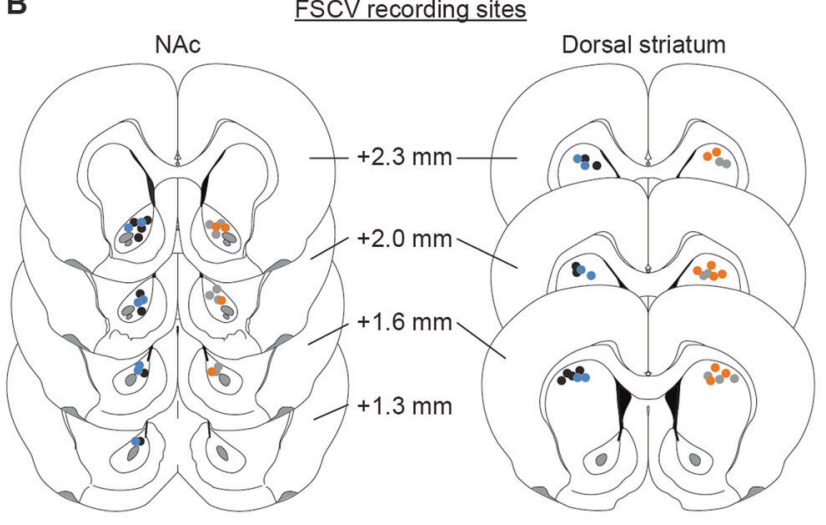

\section{Adolescents}

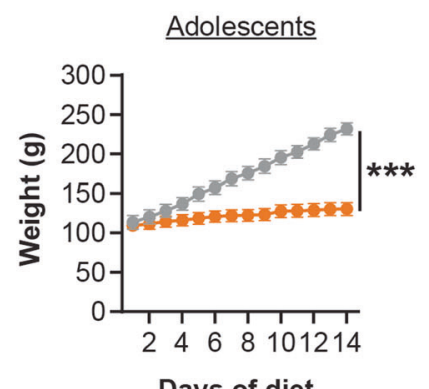

Days of diet

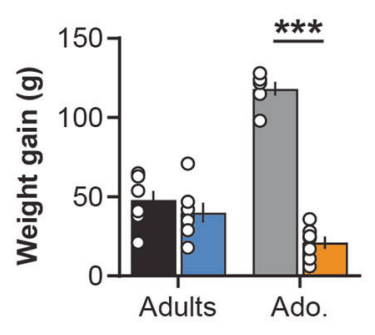

Macronutrient energy intake

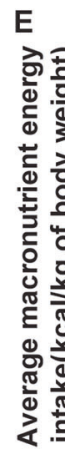

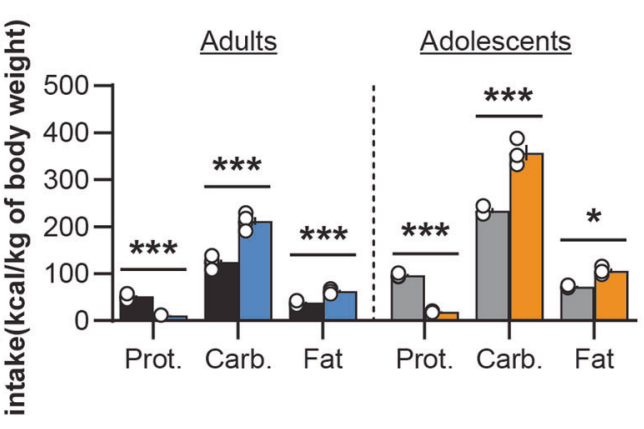

Adults

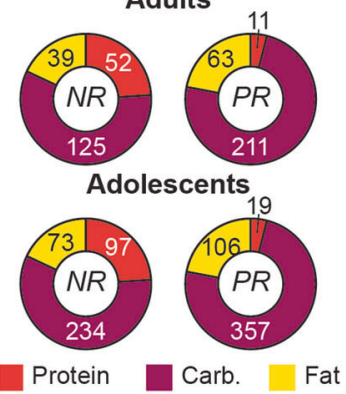

Fig. 1 Impact of protein restriction during adulthood or adolescence on body weight and food intake. a Schematic representation of the experimental design. Rats had access to either control chow diet (18\% protein; non-restricted, NR) or protein-restricted diet (5\% protein; PR) during either adolescence (postnatal days 28-42) or adulthood (postnatal days 70-82). At the end of the diet exposure, brains were extracted to perform FSCV recordings of electrically evoked dopamine (DA) release in the NAc core and dorsal striatum. DA release was measured using peak of release, area under the curve (AUC, calculated on $5 \mathrm{~s}$ time window post stimulation) and reuptake. b Coronal brain sections (modified from [83]) representing the recording sites in the NAc (left) and the dorsal striatum (right) for NR and PR groups. Numbers indicate the distance from Bregma. c Protein restriction during adolescence but not during adulthood altered weight (left and middle) and weight gain (right). d Daily energy intake (in kcal/kg of body weight) is higher in adolescent rats compared to adults, and in PR groups compared to control NR groups. e Macronutrient breakdown for daily energy intake during the diet exposure (in $\mathrm{kcal} / \mathrm{kg}$ of body weight). Pie charts represent energy intake from each macronutrient for each diet group (Protein: red; Carbohydrate: purple; Fat: yellow). Adults NR, $n=8$, black symbols; Adults PR, $n=7$, blue symbols; Adolescents NR, $n=6$, gray symbols; Adolescents PR, $n=7$, orange symbols. Data are mean \pm SEM and circles show individual (e.g., rats for $C$ and cages for $\mathrm{D}$ ) data points. ${ }^{*} p<0.05,{ }^{* *} p<0.01,{ }^{* *} p<0.001$ Diet effect (two-way ANOVA followed by Sidak's post hoc tests), $\# \#$ $p<0.001$ Age effect (two-way ANOVA).

Age, $F(1,24)=70.3, p<0.001$; Sidak's post hoc tests $p=0.4$ for Adults and $p<0.001$ for Adolescents), demonstrating that protein restriction in adolescence disrupted normal growth.

Analysis of the average daily food intake for each cage showed that adolescent rats have a higher energy intake than adults (in kcal per kg of body weight; two-way ANOVA: Age, $F(1,11)=229.8$, $p<0.001$; Fig. 1d). Moreover, PR groups also exhibited a higher daily energy intake (Diet, $F(1,11)=35.1, p<0.001$; Diet $\times$ Age, $F(1,11)=0.1, p=0.7)$. A more detailed analysis of macronutrient breakdown showed that PR groups had an lower energy intake from protein but an increased intake from carbohydrate and fat (three-way repeated measures ANOVA: Diet, $F(1,11)=35.1$, $p<0.001 ; \quad$ Diet $\times$ Macronutrient $, \quad F(2,22)=394.7, \quad p<0.001 ; \quad$ all Sidak's post hoc tests $p<0.05$; Fig. 1e and Supplementary Table 2).

After 2 weeks of protein restriction, we then assessed the neurobiological impact of this diet on dopamine release in both the NAC and the dorsal striatum using ex vivo FSCV in brain slices.

Age-dependent impact of protein restriction on NAc dopamine release

Single pulse evoked NAC dopamine release. In the NAC, protein restriction had a different impact on dopamine release evoked by single pulse stimulation depending on the life stage (Fig. 2a, b; two-way ANOVA: Age, $F(1,24)=0.1, p=0.7$; Diet, $F(1,24)=0.7$, 
A Adults
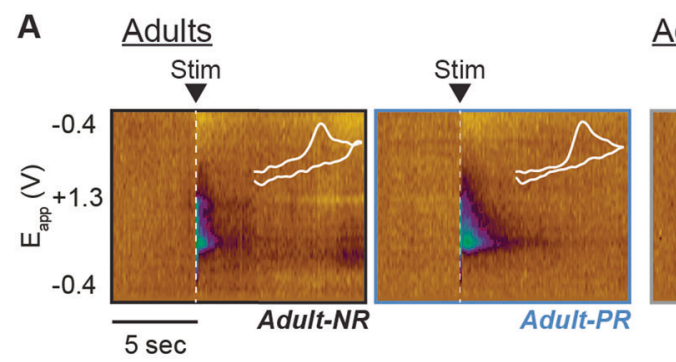

\section{Adolescents}
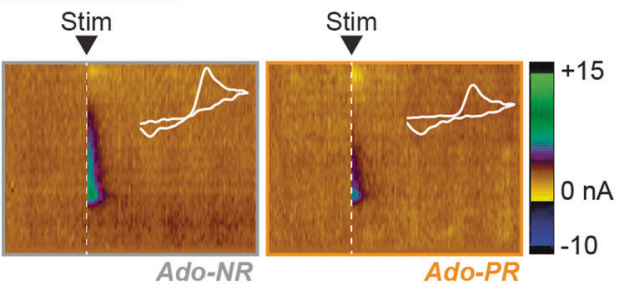

B

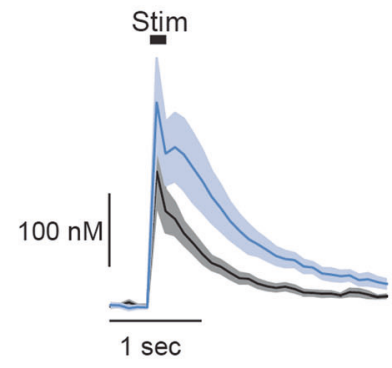

\begin{tabular}{l|l} 
NR & Adolescents \\
PR
\end{tabular}

Stim

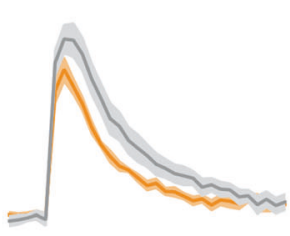

AUC

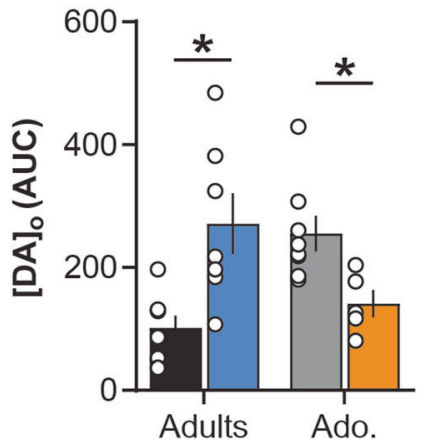

E
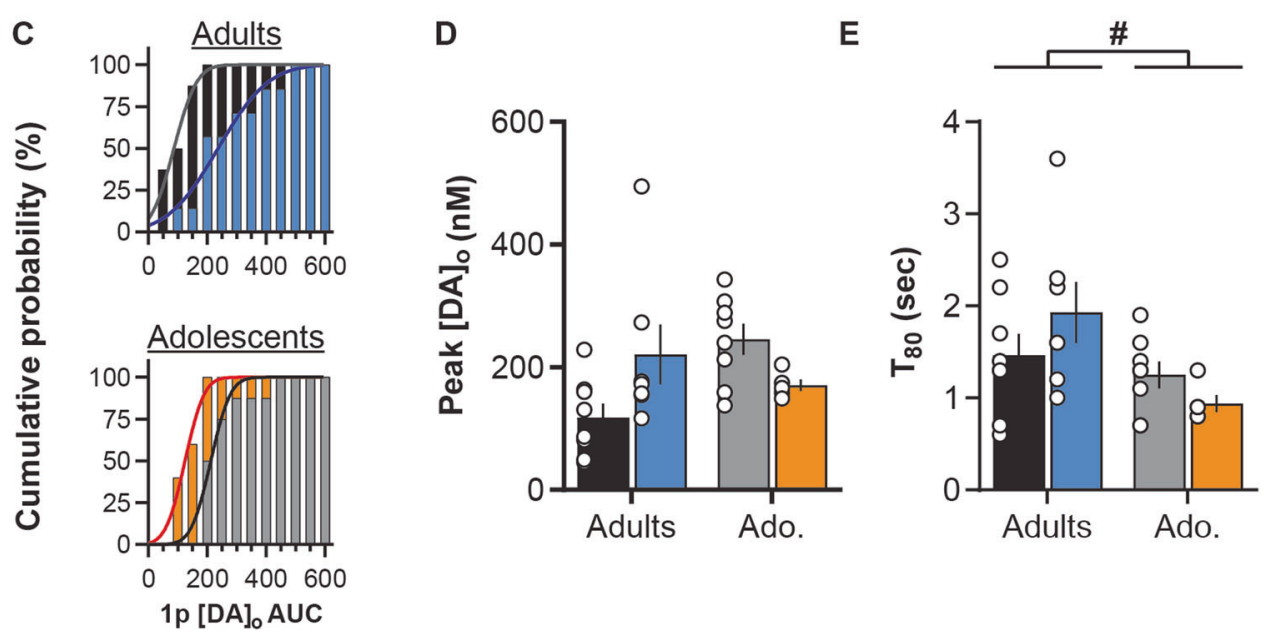

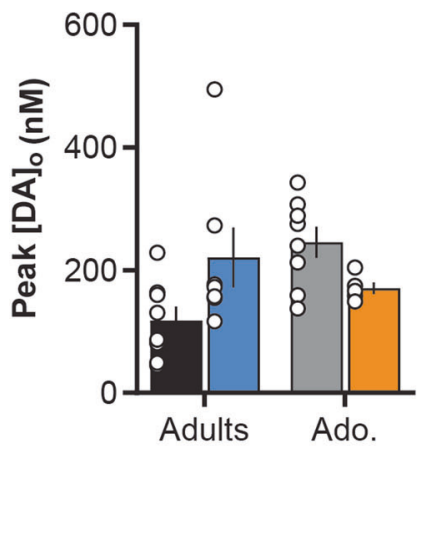

D

Fig. 2 Age-dependent impact of protein restriction on NAc dopamine release evoked by single pulse. a Representative FSCV color plots for each diet group (non-restricted, NR; protein-restricted, PR) depicting current changes (color) over time ( $x$-axis; in sec) as a function of the recording electrode holding potential ( $y$-axis; -0.4 to $+1.3 \mathrm{~V}$ and back) in response to single pulse electrical stimulation ( $0.7 \mathrm{~mA}, 0.2 \mathrm{~ms}$; vertical white dashed lines). White line insets represent voltammograms for each color plot. $\mathbf{b}$ Left: NAc [DA] $]_{\circ}$ versus time (in $n M$; mean \pm SEM) in slices from adult and adolescent NR and PR rats, aligned to the single pulse electrical stimulation (black box). [DA]。 peaks and AUC were calculated after the end of the stimulation; Right: Mean $[D A]_{0}$ release (AUC calculated on a 5 sec time window post stimulation) evoked by single pulse stimulation in the NAc. c Cumulative distribution of single pulse evoked NAc [DA $]_{\circ}$ AUC in adult (top) and adolescent (bottom) groups. d Mean $[D A]_{\circ}$ peak evoked by single pulse stimulation in the NAc. e Average $T_{80}$ (time for $80 \%$ decay from $[D A]_{0}$ peak) in the NAc. Adults NR (black, $n=8 / 5$ rats), Adults PR (blue, $n=7 / 3$ rats), Adolescents NR (gray, $n=9 / 5$ rats) and Adolescents PR (orange, $n=5 / 3$ rats). Bars show means \pm SEM and circles show individual (e.g., recording site) data points. ${ }^{*} p<0.05$ Diet effect (Student's unpaired $t$ test), ${ }^{\#} p<0.05$ Age effect (two-way ANOVA).

$p=0.4$; Diet $\times$ Age, $F(1,24)=17.8, p<0.001)$. Protein restriction at adulthood induced a significant increase $(+167 \pm 49 \%)$ in NAC dopamine release in response to single pulse stimulation compared to NR control rats (Sidak's post hoc tests $p<0.01$ ). In contrast, protein restriction during adolescence significantly decreased NAc dopamine release evoked by single pulse stimulation (Fig. 2a, b; $-44 \pm 9 \% ; p<0.05$ ). Further analyses confirmed that protein restriction in adulthood significantly changed the distribution of $[D A]_{0}$ AUC values toward the right, demonstrating a greater proportion of large dopamine responses to single pulse, compared to control animals (Fig. 2c; Kolmogorov-Smirnov test: $D(13)=0.7, p<0.05)$. In adolescents, protein restriction significantly induced a left-shift of the distribution of $[D A]_{0} A U C$, confirming a reduced dopamine response (Fig. 2c; Kolmogorov-Smirnov test: $D(11)=0.8, p<$

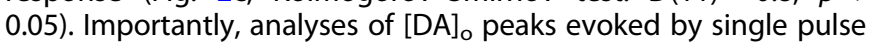
confirmed the age-dependent differential effect of the diet (Fig. 2d; two-way ANOVA: Age, $F(1,24)=1.4, p=0.2$; Diet, $F(1$, $24)=0.2, p=0.7$; Diet $\times$ Age, $F(1,24)=7.6, p<0.05)$, without revealing significant differences in either adults (Sidak's post hoc test $p=0.1$ ) or adolescent rats (Sidak's post hoc test $p=0.09$ ). To examine whether the diet-induced changes in dopamine release were mediated by differences in dopamine reuptake, we measured the $T_{80}$ clearance time. $T_{80}$ was significantly shorter in adolescent groups compared to adults (Fig. 2e; two-way ANOVA: Age, $F(1,24)=6.5, p<0.05)$. However, protein restriction at 
A
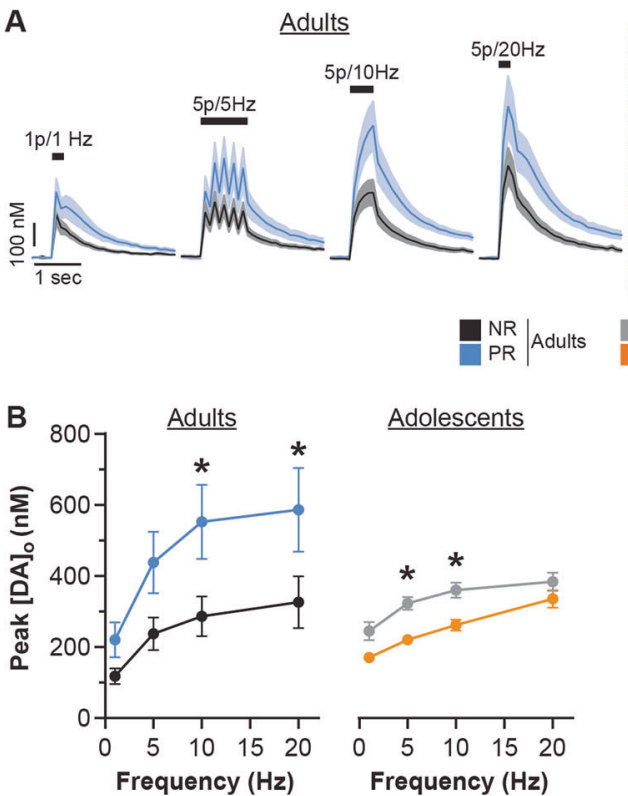

$\underline{\text { Adolescents }}$

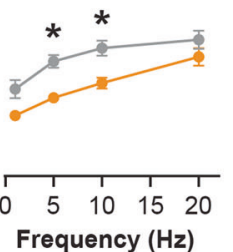

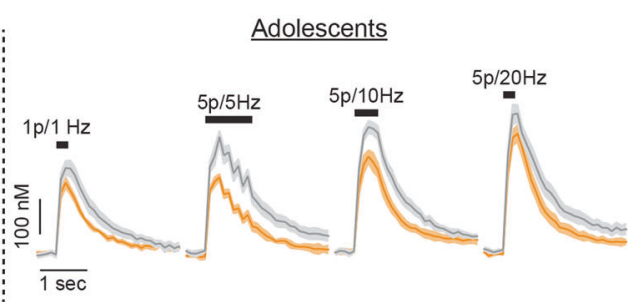

\begin{tabular}{l|l} 
NR & Adolescents \\
PR & Alo
\end{tabular}

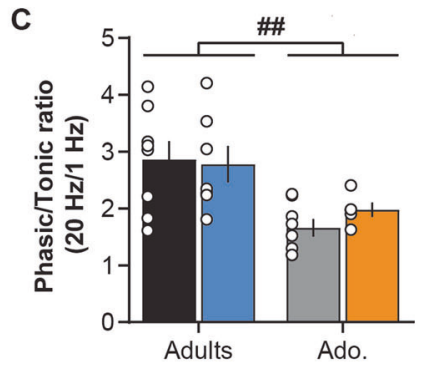

Fig. 3 Age-dependent impact of protein restriction on frequency-dependent NAc dopamine release. a NAc [DA]。 versus time (in $n M$, mean \pm SEM) for each diet group (non-restricted, NR; protein-restricted, PR) aligned to the electrical stimulation (black symbol) at $1 \mathrm{~Hz}($ single pulse), 5, 10, or $20 \mathrm{~Hz}$ (5 pulses; $0.7 \mathrm{~mA}, 0.2 \mathrm{~ms}$ ). b Protein restriction increased frequency-dependent NAc dopamine release in adult rats (left) but decreased it in adolescent rats (right; mean $[D A]_{0}$ peaks $\left.\pm S E M\right)$. c Protein restriction has no impact on NAc $[D A]_{\circ}$ phasic/tonic ratios. Adults NR (black, $n=8 / 5$ rats), Adults PR (blue, $n=7 / 3$ rats), Adolescents NR (gray, $n=9 / 5$ rats) and Adolescents PR (orange, $n=5 / 3$ rats). Bars show means \pm SEM and circles show individual (e.g., recording site) data points. ${ }^{*} p<0.05$ Diet effect (two-way ANOVA followed by Sidak's post hoc tests), ${ }^{\# \#} p<0.01$ Age effect (two-way ANOVA).

adulthood or during adolescence did not significantly change dopamine clearance (two-way ANOVA: Diet, $F(1,24)=0.1, p=0.7$; Diet $\times$ Age, $F(1,24)=2.7, p=0.1$; see also Supplementary Fig. 1). Thus, it appears that the robust changes to NAc dopamine release reported as AUC are not driven wholly by either a change to the $[D A]_{\text {o }}$ peak amplitude or the time course of dopamine uptake, but likely a combination of both factors.

Frequency-dependent NAc dopamine release. Dopamine neurons in vivo show a range of responses from low-frequency firing $(<10$ $\mathrm{Hz}$, tonic mode) to brief bursts of action potentials at high frequency $(15-25 \mathrm{~Hz}$, phasic mode) [59-62]. We therefore investigated the effect of protein restriction on dopamine release at different stimulation frequencies ranging from 1 to $20 \mathrm{~Hz}(1 \mathrm{p}=1$ $\mathrm{Hz}$, or $5 \mathrm{p}$ at 5,10 , or $20 \mathrm{~Hz}$ ). Evoked dopamine release increased with the stimulation frequency (Fig. 3a, b; three-way repeated measures ANOVA: Frequency, $F(3,72)=8.7, p<0.001)$ similarly in adolescent and adult groups (Age, $F(1,24)=1.2, p=0.3$ ). Protein restriction did not affect the frequency-dependent effect on dopamine release (Frequency $\times$ Diet, $F(3,72)=2.2, p=0.1$ ). However, protein restriction did differentially affect NAc dopamine release depending on age (Diet, $F(1,24)=1.4, p=0.2$; Age $\times$ Diet $F(1,24)=7.2, p<0.01$; Frequency $\times$ Diet $\times$ Age, $F(3,72)=2.1, p=$ 0.1 ; see also Supplementary Fig. 2).

In adult rats, protein restriction increased dopamine release in response to the range of stimulation frequencies (two-way repeated measures ANOVA: Diet, $F(1,13)=4.7, p<0.05$; Frequency, $F(3,39)=30.0, p<0.001$; Diet $\times$ Frequency, $F(3,39)=2.6$, $p=0.06)$. Conversely, protein restriction during adolescence significantly decreased evoked NAc dopamine release (two-way repeated measures ANOVA: Diet, $F(1,11)=9.8, p<0.01$; Frequency, $F(3,33)=35.6, p<0.001$; Diet $\times$ Frequency, $F(3,33)=1.3$, $p=0.3$ ). These results were also confirmed by the measure of dopamine release calculated as the AUC (see Supplementary Fig. 2). The relationship between dopamine release during tonic and phasic activity is a central process in the signaling of significant environmental events and learning $[62,65,66]$. We examined whether protein restriction during either adolescence or adulthood affected the 'phasic/tonic ratio' of NAc dopamine release $(5 p$ at $20 \mathrm{~Hz} / 1$ p, Fig. 3c). Adolescent rats exhibited a lower ratio than adult rats (two-way ANOVA: Age, $F(1,24)=13.9, p<$ $0.01)$. However, protein restriction did not alter this ratio at either age $($ Diet, $F(1,24)=0.2, p=0.7$; Age $\times$ Diet, $F(1,24)=0.6, p=0.5)$, highlighting the general impact of protein restriction on dopamine release to both low and high frequency stimulations in all age conditions.

Age-dependent impact of protein restriction on dorsal striatum dopamine release

Single pulse evoked dorsal striatum dopamine release. In the dorsal striatum, protein restriction had no effect on dopamine release evoked by single pulse stimulation whether rats were exposed to the diet during adulthood or adolescence (Fig. 4a, b; two-way ANOVA: Age, $F(1,28)=0.7, p=0.4$; Diet, $F(1,28)=0.01$, $p=0.9$; Diet $\times$ Age, $F(1,28)=1.3, p=0.3)$, which is also confirmed by the distribution analysis (Fig. 4c; Kolmogorov-Smirnov tests: Adult groups, $D(14)=0.3, p=0.8$; Adolescent groups, $D(14)=0.6$, $p=0.1$ ). Moreover, protein restriction also did not significantly affect $[D A]_{\circ}$ peak amplitude (Fig. 4d; two-way ANOVA: Diet, $F(1,28)=0.04, p=0.9$; Age, $F(1,28)=0.08, p=0.8$, Diet $\times$ Age, $F(1,28)=1.4, p=0.2$ ) or dopamine clearance (Fig. 4e; two-way ANOVA: Diet, $F(1,28)=0.03, p=0.9 ;$ Age, $F(1,28)=0.9, p=0.4$, Diet $\times$ Age, $F(1,28)=2.1, p=0.2$; see also Supplementary Fig. 1 ).

Frequency-dependent dorsal striatum dopamine release. Striatal dopamine release increased as a function of the stimulation frequency (Fig. 5a, b; three-way repeated measures ANOVA: Frequency, $F(3,84)=81.6, p<0.001$; Age, $F(1,28)=5.8, p<0.05$; Frequency $\times$ Age, $F(3,84)=16.9, p<0.001$; see also Supplementary Fig. 2B). However, protein restriction differentially impacted dopamine release evoked by low and high stimulation frequencies (Diet, $F(1,28)=2.2, p=0.1$; Diet $\times$ Frequency, $F(3,84)=6.7, p<$ 0.001 ; Diet $\times$ Age $F(1,28)=0.4, p=0.5$; Diet $\times$ Frequency $\times$ Age, $F(3,84)=0.8, p=0.5)$. Separate analyses for each age group 
A $\quad$ Adults
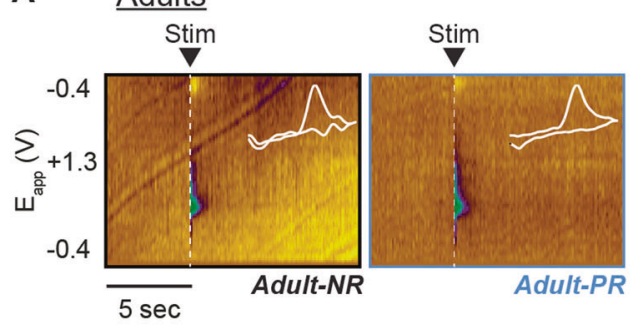

B

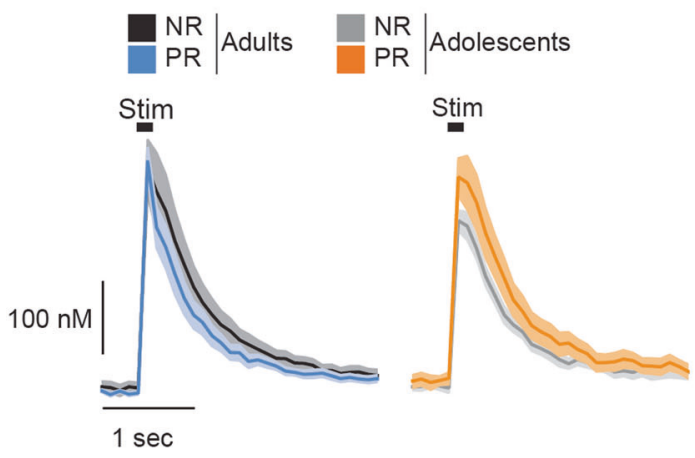

C

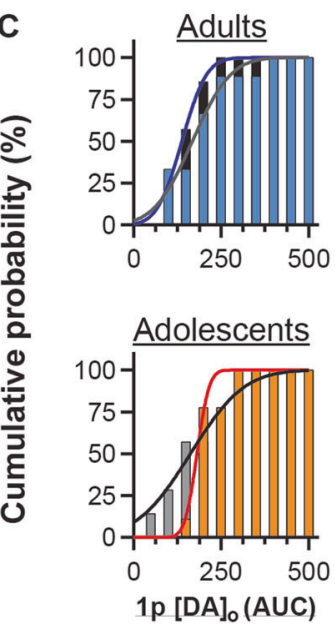

Adolescents
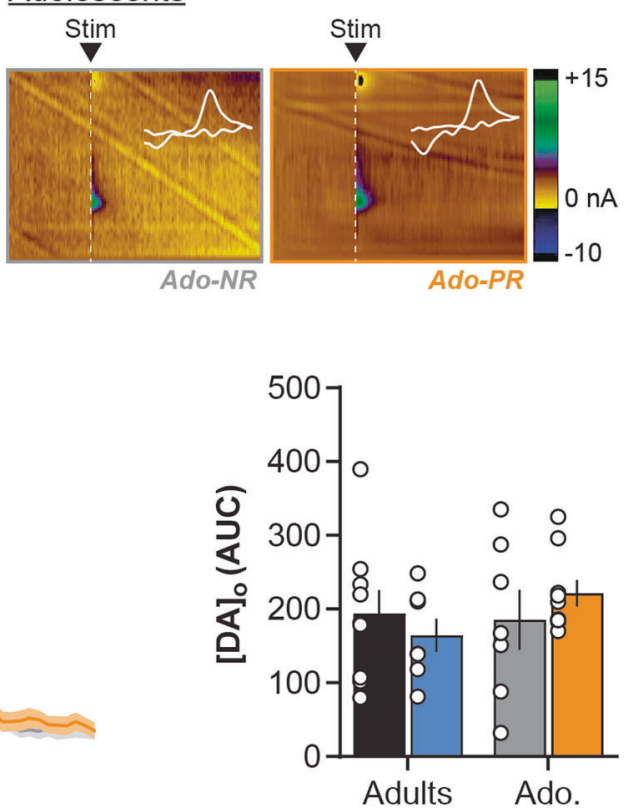

E

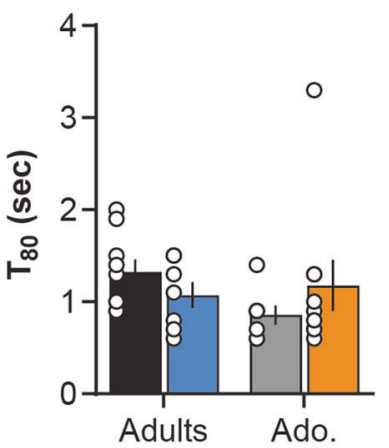

Fig. 4 Age-dependent impact of protein restriction on dorsal striatum dopamine release evoked by single pulse. a Representative FSCV color plots for each diet group (non-restricted, NR; protein-restricted, PR) depicting current changes (color) over time ( $x$-axis; in sec) as a function of the recording electrode holding potential ( $y$-axis; -0.4 to $+1.3 \mathrm{~V}$ and back) in response to single pulse electrical stimulation $(0.7 \mathrm{~mA}, 0.2 \mathrm{~ms}$; vertical white dashed lines). White line insets represent voltammograms for each color plot. b Left: Dorsal striatum [DA] (in $\mathrm{nM}$; mean $\pm \mathrm{SEM}$ ) in slices from adult and adolescent NR and PR rats, aligned to the single pulse electrical stimulation (black box). [DA] $]_{0}$ peaks and AUC were calculated after the end of the stimulation; right: [DA $]_{\circ}$ release (AUC calculated on a $5 \mathrm{~s}$ time window post stimulation) evoked by single pulse stimulation in the dorsal striatum. c Cumulative distribution of single pulse evoked dorsal striatum [DA $]_{\circ} A U C$ in adult (top) and adolescent (bottom) groups. d Mean [DA] o peak evoked by single pulse stimulation in the dorsal striatum. e Average $T_{80}$ (time for $80 \%$ decay from $[D A]_{\circ}$ peak) in the dorsal striatum. Adults NR (black, $n=9 / 4$ rats), Adults PR (blue, $n=7 / 4$ rats), Adolescents NR (gray, $n=7 / 3$ rats) and Adolescents PR (orange, $n=9 / 4$ rats). Bars show means \pm SEM and circles show individual (e.g., recording site) data points.

confirmed that protein restriction has no significant effect on frequency-dependent striatal dopamine release in adults (two-way repeated measures ANOVA: Diet, $F(1,14)=0.2, p=0.6$; Frequency, $F(3,42)=63.8, p<0.001$; Diet $\times$ Frequency, $F(3,42)=4.2, p<0.05$; Sidak's post hoc tests: all $p>0.7)$. In contrast, protein restriction in adolescent rats significantly increased stimulation-evoked striatal dopamine release (two-way repeated measures ANOVA: Diet, $F(1,14)=4.8, p<0.05$; Frequency, $F(3,42)=19.2, p<0.001$; Diet $\times$ Frequency, $F(3,42)=2.7, p=0.05)$, especially in response to phasic-like stimulations (Sidak's post hoc tests: $1-10 \mathrm{~Hz}$ all $p>0.1$; $20 \mathrm{~Hz} p<0.01)$. Moreover, both low and high stimulation frequencies increased dopamine release in the adolescent PR group (Dunnett's post hoc tests versus $1 \mathrm{~Hz}$ stimulation: $5 \mathrm{~Hz}$, $p<0.01 ; 10 \mathrm{~Hz}, p<0.001 ; 20 \mathrm{~Hz}, p<0.001)$, whereas this is only observed for high frequencies in the NR control group $(5 \mathrm{~Hz}, p=$ $0.3 ; 10 \mathrm{~Hz}, p<0.01 ; 20 \mathrm{~Hz}, p<0.001)$. Similar results were observed by measuring the AUC of dopamine evoked release (see Supplementary Fig. 2). These results suggest that the nigrostriatal dopamine system may be sensitized by protein restriction during adolescence, despite an overall decrease in evoked release of dopamine.

Similar to what we observed in the NAc, the 'phasic/tonic' ratio of striatal dopamine release was lower in adolescent slices (Fig. 5c; Two-way ANOVA: Age, $F(1,28)=11.7, p<0.01)$ but was not altered by protein restriction (Diet, $F(1,28)=1.8, p=0.2$; Age $\times$ Diet, $F(1,28)=0.001, p=1.0)$. 
A Adults
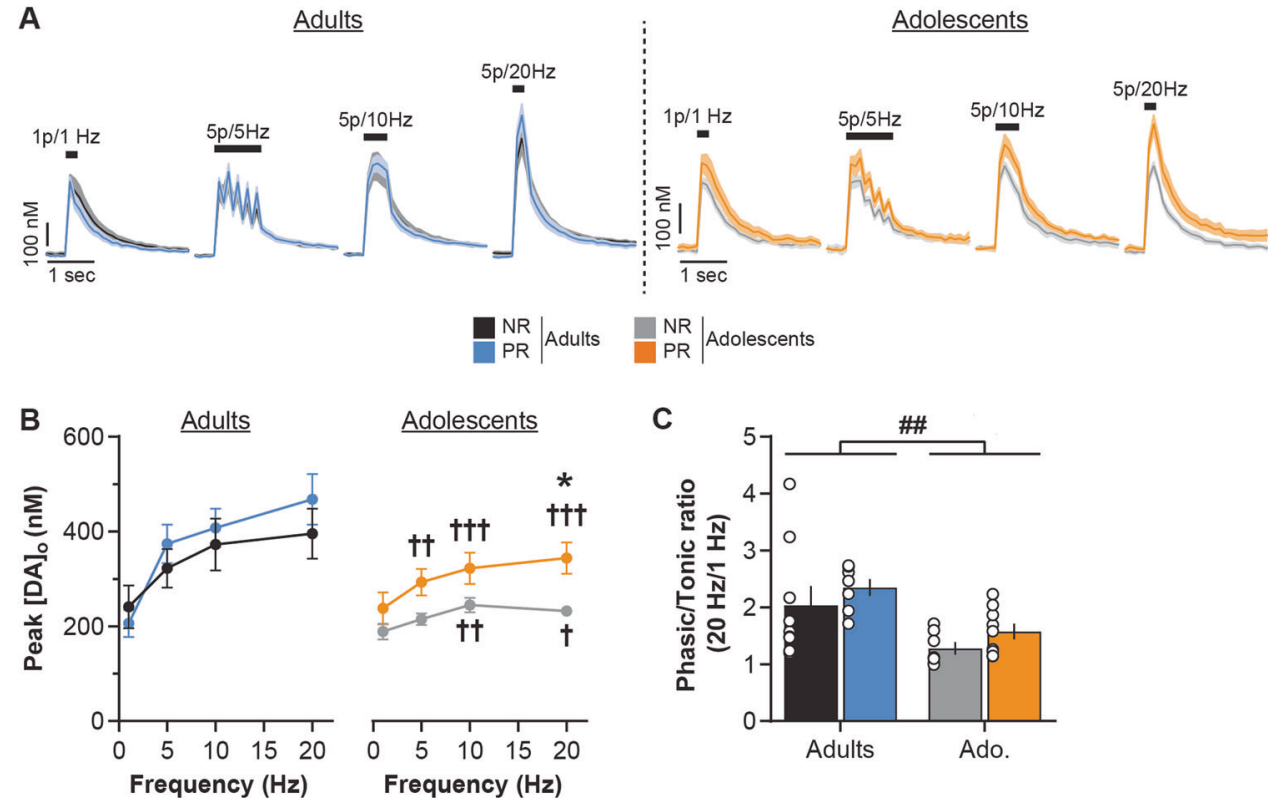

Fig. 5 Age-dependent impact of protein restriction on frequency-dependent dorsal striatum dopamine release. a Dorsal striatum $[D A]_{\circ}$ (in $\mathrm{nM}$, mean $\pm \mathrm{SEM}$ ) for each diet group (non-restricted, NR; protein-restricted, PR) aligned to the electrical stimulation (black symbol) at $1 \mathrm{~Hz}$ (single pulse), 5, 10, or $20 \mathrm{~Hz}$ (5 pulses; $0.7 \mathrm{~mA}, 0.2 \mathrm{~ms}$ ). b Protein restriction at adulthood did not affect dorsal striatum dopamine release in adults (left) but increased it in adolescent rats (right; mean $[D A]_{\circ}$ peaks $\left.\pm S E M\right)$. c Protein restriction has no impact on $[D A]_{\circ}$ phasic/tonic ratios. Adults NR (black, $n=9 / 4$ rats), Adults PR (blue, $n=7 / 4$ rats), Adolescents NR (gray, $n=7 / 3$ rats) and Adolescents PR (orange, $n=9 / 4$ rats). Bars show means \pm SEM and circles show individual (e.g., recording site) data points. ${ }^{*} p<0.05$ Diet effect (two-way ANOVA followed by Sidak's post hoc tests), ${ }^{\dagger+} p<0.01,{ }^{+\dagger+} p<0.001$ Frequency effect (two-way ANOVA followed by Dunnett's post hoc tests versus $1 \mathrm{~Hz}$ ), ${ }^{\# \#} p<0.01 \mathrm{Age}$ effect (two-way ANOVA).

\section{DISCUSSION}

Protein homeostasis is a crucial physiological function for almost all species throughout the lifespan. Despite the deleterious consequences of protein restriction on a multitude of physiological functions, the neurobiological impact of such a diet at different ages remains largely unexplored. The present study reveals that protein restriction affects the function of the mesolimbic and nigrostriatal dopamine pathways. More importantly, our results demonstrate that these effects are dependent on the age at which protein restriction is experienced, highlighting adolescence as a vulnerability window for the deleterious effects of an unbalanced diet.

The impact of protein restriction on weight is highly dependent on the degree of restriction and the physiological state of the animal $[9,10,55]$. When performed at adulthood, protein restriction did not affect rats' weight, consistent with our previous results [11]. Moreover, adult rats slightly increased their daily energy intake relative to their body weight. In adults, this increase may explain the absence of effect on weight as rats attempt to compensate protein deficiency with a general hyperphagia [11]. An alternative explanation is that low protein diet may change energy expenditure, as previously observed [67]. In contrast, protein restriction during adolescence significantly limits animals' normal trajectory of weight gain. As for adults, adolescent PR rats increased their daily energy intake compared to the control NR group. Adolescent animals are rapidly growing and have higher protein requirements than adults [55]. Surprisingly, this change in food intake behavior did not seem to be sufficient to support normal growth. In the present study, the low protein diet (5\% protein from casein) was the only source of nutrients. Breakdown analysis of macronutrient intake revealed that the important protein deficiency observed in PR groups is associated with an indirect increase in carbohydrate and fat intake contained in animal food. The regulation of protein appetite and the balance between protein intake and other macronutrients is still poorly understood but several studies suggest that numerous species regulate their food-related behaviors to avoid protein deficiency [8-10], which may lead to the overconsumption of other nutrients. It remains intriguing, however, that in this case adolescent PR rats did not exhibit a larger increase of their food intake. As both the overconsumption of sweet or fat diets may impact the functioning of the dopamine system especially during development [43-47], we cannot exclude that the diet impact reported here may be the result of the combination of protein deficiency and concurrent changes in carbohydrate and fat intake.

The two main dopamine projections to the NAc and the dorsal striatum are involved in various food-related processes including incentive salience [16] and prediction error [66], using taste and nutritional (post-ingestive) values of food [23-28]. Here, we observed that protein restriction differentially affected projection-specific dopamine release depending on age of diet exposure. At adulthood, protein restriction increased NAC dopamine release but had no effect on dorsal striatum dopamine release. Tonic and phasic dopamine firing and release convey different information about motivational and learning processes $[16,19,23,66,68]$. In the mesolimbic pathway, PR diet at adulthood increased both responses to low 'tonic' and high 'phasic' stimulations but did not alter the phasic/tonic ratio, suggesting a more general increase in the capacity of terminals for dopamine release rather than a change in the contrast between different dopamine signaling modes $[59,69]$. Such global sensitization of the mesolimbic pathway may profoundly alter motivated behaviors like food preferences $[11,13]$, and increase the rewarding properties of protein-enriched food in restricted/deprived animals [12].

Protein restriction during adolescence had a broader impact on the function of dopamine terminals, relative to the same diet during adulthood. In contrast to what we observed at adulthood, protein restriction in adolescents decreased NAc dopamine release both in response to single pulse stimulation, lowfrequency pulse trains $(5-10 \mathrm{~Hz})$ and high frequency burst-like stimulation $(5 p$ at $20 \mathrm{~Hz})$. Dopamine neurons exhibit an elevated firing rate during adolescence $[50,53,54]$ associated with changes in dopamine availability in dopamine projection targets 
$[48,49,51]$. Based on this and our first results showing an effect of protein restriction at adulthood on NAc dopamine release, we might have expected an enhancement of the diet effect during adolescence. One way to reconcile these opposite findings is to consider that the degree of protein restriction in adolescent rats may be more profound than in adults. As discussed earlier, we observed a substantial impact of protein restriction on weight gain in protein-restricted adolescents (and not in adults) suggesting a more severe level of restriction. As dietary protein is a major source of amino acids (e.g., tyrosine) required for catecholaminergic metabolism (synthesis, release, and enzymatic activity), one hypothesis is that a greater protein deficiency in adolescent rats than adults will affect average dopamine levels and the ability to synthesize and release dopamine. Accordingly, previous studies have reported a decrease in dopamine in several brain regions in response to pre- or perinatal protein malnutrition as well as an hypo-responsivity to psychostimulants (see [5] for review).

In the dorsal striatum in adolescents, we observed an opposite pattern compared to the NAc. As such, evoked dopamine release was increased after adolescent protein restriction, especially at high stimulation frequencies. Such an effect partially rules out the hypothesis of a global amino acid deficiency. However, the nigrostriatal dopamine pathway matures earlier than other dopamine pathways [48] and may then be less sensitive to protein restriction. Striatal and NAc dopamine pathways are involved in different aspects of food-related processes and recent advances demonstrated that striatal, but not NAc, dopamine signaling is involved in encoding the nutritional value of food [70]. The increase in evoked dopamine release in striatal areas only seen in adolescentexposed rats reported in the present study may support a nutritionseeking response to the elevated protein requirement at this age.

The effect of protein restriction at adulthood or during adolescence on dopamine pathways may also involve regulation of dopamine terminal activity by reuptake processes or local striatal microcircuits $[65,69]$. Dopamine reuptake activity may be changed by specific diets $[39,40]$. Here, we did not observe any significant change induced by protein restriction on dopamine clearance in response to single pulse stimulations. Combined with the absence of significant diet effects on the $[D A]_{0}$ peak amplitudes, this suggests that neither protein restriction during adolescence nor adulthood impacts dopamine transporter functioning [71-74]. However, we cannot totally exclude reuptake changes as we observed diet-dependent changes in evoked dopamine release quantified by AUC. The AUC could vary because of changes in either dopamine release or reuptake. On the other hand, striatal microcircuits also mature during adolescence $[75,76]$ and may be sensitive to different diet effects. These issues and the behavioral consequences of dietary protein alterations on the dopamine system remain to be investigated.

The direct influence of protein or amino acids levels on dopamine neurons is still unexplored, however, these neurons receive input from hypothalamic regions which are able to detect amino acids [10, 14]. Protein restriction also induces a broad metabolic response involving peripheral food-related signals to which dopamine neurons are directly sensitive [31-35]. Dopamine release is especially sensitive to insulin through its actions at specific receptors located both directly on dopamine neurons [77] and on striatal cholinergic neurons [37]. The effects of insulin on the dopamine system and dopamine-related behaviors are complex and depend on insulin concentration, brain region, cell type, and the current physiological state [40, 78]. Protein restriction is known to increase insulin sensitivity and glucose metabolism [13, 79], which may then modulate dopamine's neurobiological and behavioral functions. The interaction of the dopamine and insulin systems in response to different diets differing in protein content warrants further ex vivo and in vivo investigation.
In conclusion, our study provides evidence that prolonged protein restriction has an important impact on the function of dopamine terminals in the NAc and dorsal striatum. More importantly we highlight the increased sensitivity of the dopamine system during adolescence to the deleterious effects of a diet that is inadequate in protein. Adolescence is characterized by important maturation events within dopamine circuitry and dopamine-related processes [48-52, 54] and numerous studies have now demonstrated that adolescence is an important vulnerability window for diet-related alterations of cognitive and neurobiological functions [43-47]. How protein restriction during adolescence may have different, and potentially long-term, impacts on dopamine-related behaviors considering its opposite effects on the mesolimbic and nigrostriatal pathways, remains to be investigated. Given the role of malnutrition and inadequate protein intake on neurodevelopmental psychiatric disorders $[5,6]$ involving alterations of the dopamine system $[17,80,81]$ and having their onset during adolescence [36, 82], our current findings also represent a step toward a better understanding of the mechanisms regulating protein appetite, protein malnutrition, and the emergence of dopamine-related disorders.

\section{FUNDING AND DISCLOSURE}

This work was supported by the Biotechnology and Biological Sciences Research Council [grant \#BB/M007391/1 to JEM], the European Commission [grant \#GA 631404 to JEM], The Leverhulme Trust [grant \#RPG-2017-417 to JEM] and the Tromsø Research Foundation [grant \#19-SG-JMcC to JEM). The authors declare no competing interests.

\section{ACKNOWLEDGEMENTS}

The authors would like to acknowledge the help and support from the staff of the Division of Biomedical Services, Preclinical Research Facility, University of Leicester for technical support and the care of experimental animals.

\section{AUTHOR CONTRIBUTIONS}

FN, KZP, and JEM designed research; FN performed research, FN, KZP, AMJY, and JEM analyzed data; FN, KZP, AMJY, and JEM wrote the paper.

\section{ADDITIONAL INFORMATION}

Supplementary Information accompanies this paper at (https://doi.org/10.1038/ s41386-020-0783-z)

Publisher's note Springer Nature remains neutral with regard to jurisdictional claims in published maps and institutional affiliations.

\section{REFERENCES}

1. Berthoud H-R, Münzberg $H$, Richards BK, Morrison CD. Neural and metabolic regulation of macronutrient intake and selection. Proc Nutr Soc 2012;71:390-400

2. Simpson SJ, Raubenheimer D. Obesity: the protein leverage hypothesis. Obes Rev. 2005;6:133-42.

3. Hall KD. The potential role of protein leverage in the US obesity epidemic. Obesity. 2019;27:1222-4.

4. Raubenheimer D, Simpson SJ. Protein leverage: theoretical foundations and ten points of clarification. Obesity. 2019;27:1225-38.

5. Alamy $M$, Bengelloun WA. Malnutrition and brain development: an analysis of the effects of inadequate diet during different stages of life in rat. Neurosci Biobehav Rev. 2012;36:1463-80.

6. Grissom NM, Reyes TM. Gestational overgrowth and undergrowth affect neurodevelopment: similarities and differences from behavior to epigenetics. Int J Dev Neurosci. 2013:31:406-14.

7. Gould JM, Smith PJ, Airey CJ, Mort EJ, Airey LE, Warricker FDM, et al. Mouse maternal protein restriction during preimplantation alone permanently alters 
brain neuron proportion and adult short-term memory. Proc Natl Acad Sci USA. 2018;115:E7398-E7407.

8. Theall CL, Wurtman JJ, Wurtman RJ. Self-selection and regulation of protein: carbohydrate ratio in foods adult rats eat. J Nutr. 1984;114:711-8.

9. Morrison CD, Reed SD, Henagan TM. Homeostatic regulation of protein intake: in search of a mechanism. Am J Physiol Regul Integr Comp Physiol. 2012;302: R917-928.

10. Morrison CD, Laeger T. Protein-dependent regulation of feeding and metabolism. Trends Endocrinol Metab. 2015;26:256-62.

11. Murphy M, Peters KZ, Denton BS, Lee KA, Chadchankar H, McCutcheon JE. Restriction of dietary protein leads to conditioned protein preference and elevated palatability of protein-containing food in rats. Physiol Behav. 2018;184:235-41.

12. Naneix F, Peters KZ, McCutcheon JE. Investigating the effect of physiological need states on palatability and motivation using microstructural analysis of licking. Neuroscience. 2019. https://doi.org/10.1016/j.neuroscience.2019.10.036. 1 November 2019.

13. Hill CM, Laeger $T$, Dehner $M$, Albarado DC, Clarke B, Wanders $D$, et al. FGF21 signals protein status to the brain and adaptively regulates food choice and metabolism. Cell Rep. 2019;27:2934-.e3.

14. Heeley N, Blouet C. Central amino acid sensing in the control of feeding behavior. Front Endocrinol. 2016;7:148

15. von Holstein-Rathlou S, BonDurant LD, Peltekian L, Naber MC, Yin TC, Claflin KE, et al. FGF21 mediates endocrine control of simple sugar intake and sweet taste preference by the liver. Cell Metab. 2016;23:335-43.

16. Berridge KC. The debate over dopamine's role in reward: the case for incentive salience. Psychopharmacology. 2007;191:391-431.

17. Volkow ND, Wang G-J, Baler RD. Reward, dopamine and the control of food intake: implications for obesity. Trends Cogn Sci. 2011;15:37-46.

18. Liu CM, Kanoski SE. Homeostatic and non-homeostatic controls of feeding behavior: distinct vs. common neural systems. Physiol Behav. 2018;193:223-31.

19. Saunders BT, Richard JM, Margolis EB, Janak PH. Dopamine neurons create Pavlovian conditioned stimuli with circuit-defined motivational properties. Nat Neurosci. 2018;21:1072-83.

20. McCutcheon JE. The role of dopamine in the pursuit of nutritional value. Physiol Behav. 2015;152:408-15.

21. Aitken TJ, Greenfield VY, Wassum KM. Nucleus accumbens core dopamine signaling tracks the need-based motivational value of food-paired cues. J Neurochem. 2016;136:1026-36

22. Papageorgiou GK, Baudonnat M, Cucca F, Walton ME. Mesolimbic dopamine encodes prediction errors in a state-dependent manner. Cell Rep. 2016;15:221-8.

23. Hsu TM, McCutcheon JE, Roitman MF. Parallels and overlap: the integration of homeostatic signals by mesolimbic dopamine neurons. Front Psychiatry. 2018;9:410.

24. de Araujo IE, Ren X, Ferreira JG. Metabolic sensing in brain dopamine systems. Results Probl Cell Differ. 2010;52:69-86.

25. Domingos Al, Vaynshteyn J, Voss HU, Ren X, Gradinaru V, Zang F, et al. Leptin regulates the reward value of nutrient. Nat Neurosci. 2011;14:1562-8.

26. Beeler JA, McCutcheon JE, Cao ZFH, Murakami M, Alexander E, Roitman MF, et al. Taste uncoupled from nutrition fails to sustain the reinforcing properties of food. Eur J Neurosci. 2012;36:2533-46.

27. McCutcheon JE, Beeler JA, Roitman MF. Sucrose-predictive cues evoke greater phasic dopamine release than saccharin-predictive cues. Synapse. 2012;66:346-51.

28. Alhadeff AL, Goldstein N, Park O, Klima ML, Vargas A, Betley JN. Natural and drug rewards engage distinct pathways that converge on coordinated hypothalamic and reward circuits. Neuron. 2019:103:891-908.e6.

29. Sclafani A, Touzani K, Bodnar RJ. Dopamine and learned food preferences. Physiol Behav. 2011;104:64-68.

30. Han W, Tellez LA, Perkins MH, Perez IO, Qu T, Ferreira J, et al. A neural circuit for gut-induced reward. Cell. 2018;175:665-.e23.

31. Fulton S, Pissios P, Manchon RP, Stiles L, Frank L, Pothos EN, et al. Leptin regulation of the mesoaccumbens dopamine pathway. Neuron. 2006;51:811-22.

32. Hommel JD, Trinko R, Sears RM, Georgescu D, Liu Z-W, Gao X-B, et al. Leptin receptor signaling in midbrain dopamine neurons regulates feeding. Neuron. 2006;51:801-10.

33. Cone JJ, McCutcheon JE, Roitman MF. Ghrelin acts as an interface between physiological state and phasic dopamine signaling. J Neurosci. 2014;34:4905-13.

34. Mietlicki-Baase EG, Ortinski PI, Reiner DJ, Sinon CG, McCutcheon JE, Pierce RC, et al. Glucagon-like peptide-1 receptor activation in the nucleus accumbens core suppresses feeding by increasing glutamatergic AMPA/kainate signaling. J Neurosci. 2014;34:6985-92.

35. Liu S, Borgland SL. Regulation of the mesolimbic dopamine circuit by feeding peptides. Neuroscience. 2015;289:19-42.
36. Avena NM, Rada P, Hoebel BG. Evidence for sugar addiction: behavioral and neurochemical effects of intermittent, excessive sugar intake. Neurosci Biobehav Rev. 2008;32:20-39.

37. Stouffer MA, Woods CA, Patel JC, Lee CR, Witkovsky P, Bao L, et al. Insulin enhances striatal dopamine release by activating cholinergic interneurons and thereby signals reward. Nat Commun. 2015;6:8543.

38. Décarie-Spain L, Hryhorczuk C, Fulton S. Dopamine signalling adaptations by prolonged high-fat feeding. Curr Opin Behav Sci. 2016;9:136-43.

39. Fordahl SC, Locke JL, Jones SR. High fat diet augments amphetamine sensitization in mice: role of feeding pattern, obesity, and dopamine terminal changes. Neuropharmacology. 2016;109:170-82.

40. Fordahl SC, Jones SR. High-fat-diet-induced deficits in dopamine terminal function are reversed by restoring insulin signaling. ACS Chem Neurosci. 2017;8:290-9.

41. Naef L, Moquin L, Dal Bo G, Giros B, Gratton A, Walker C-D. Maternal high-fat intake alters presynaptic regulation of dopamine in the nucleus accumbens and increases motivation for fat rewards in the offspring. Neuroscience. 2011;176:225-36.

42. Grissom NM, Herdt CT, Desilets J, Lidsky-Everson J, Reyes TM. Dissociable deficits of executive function caused by gestational adversity are linked to specific transcriptional changes in the prefrontal cortex. Neuropsychopharmacology. 2015;40:1353-63.

43. Naneix F, Darlot F, Coutureau E, Cador M. Long-lasting deficits in hedonic and nucleus accumbens reactivity to sweet rewards by sugar overconsumption during adolescence. Eur J Neurosci. 2016;43:671-80.

44. Naneix F, Tantot F, Glangetas C, Kaufling J, Janthakhin $Y$, Boitard C, et al. Impact of early consumption of high-fat diet on the mesolimbic dopaminergic system. ENeuro. 2017:4:0120-17.

45. Naneix F, Darlot F, De Smedt-Peyrusse V, Pape JR, Coutureau E, Cador M. Protracted motivational dopamine-related deficits following adolescence sugar overconsumption. Neuropharmacology. 2018;129:16-25.

46. Noble EE, Kanoski SE. Early life exposure to obesogenic diets and learning and memory dysfunction. Curr Opin Behav Sci. 2016;9:7-14.

47. Reichelt AC. Adolescent maturational transitions in the prefrontal cortex and dopamine signaling as a risk factor for the development of obesity and high fat/ high sugar diet induced cognitive deficits. Front Behav Neurosci. 2016;10:189.

48. Spear LP. The adolescent brain and age-related behavioral manifestations. Neurosci Biobehav Rev. 2000;24:417-63.

49. Andersen SL. Trajectories of brain development: point of vulnerability or window of opportunity? Neurosci Biobehav Rev. 2003;27:3-18.

50. McCutcheon JE, Conrad KL, Carr SB, Ford KA, McGehee DS, Marinelli M. Dopamine neurons in the ventral tegmental area fire faster in adolescent rats than in adults. J Neurophysiol. 2012;108:1620-30.

51. Naneix F, Marchand AR, Di Scala G, Pape J-R, Coutureau E. Parallel maturation of goal-directed behavior and dopaminergic systems during adolescence. J Neurosci. 2012;32:16223-32.

52. Naneix F, Marchand AR, Pichon A, Pape J-R, Coutureau E. Adolescent stimulation of $D 2$ receptors alters the maturation of dopamine-dependent goal-directed behavior. Neuropsychopharmacology. 2013;38:1566-74.

53. McCutcheon JE, Marinelli M. Age matters. Eur J Neurosci. 2009;29:997-1014.

54. Marinelli M, McCutcheon JE. Heterogeneity of dopamine neuron activity across traits and states. Neuroscience. 2014;282:176-97.

55. White BD, Porter MH, Martin RJ. Effects of age on the feeding response to moderately low dietary protein in rats. Physiol Behav. 2000;68:673-81.

56. Fortin SM, Cone JJ, Ng-Evans S, McCutcheon JE, Roitman MF. Sampling phasic dopamine signaling with fast-scan cyclic voltammetry in awake, behaving rats. Curr Protoc Neurosci. 2015;70:7.25.1-7.25.20.

57. Mauterer M, Estave P, Holleran K, Jones S. Measurement of dopamine using fast scan cyclic voltammetry in rodent brain slices. Bio-Protocol. 2018;8:e2473.

58. Heien MLAV, Johnson MA, Wightman RM. Resolving neurotransmitters detected by fast-scan cyclic voltammetry. Anal Chem. 2004;76:5697-704.

59. Rice ME, Cragg SJ. Nicotine amplifies reward-related dopamine signals in striatum. Nat Neurosci. 2004;7:583-4.

60. Grace AA, Bunney BS. Intracellular and extracellular electrophysiology of nigral dopaminergic neurons-1. Identification and characterization. Neuroscience. 1983;10:301-15.

61. Hyland BI, Reynolds JNJ, Hay J, Perk CG, Miller R. Firing modes of midbrain dopamine cells in the freely moving rat. Neuroscience. 2002;114:475-92.

62. Grace AA, Floresco SB, Goto Y, Lodge DJ. Regulation of firing of dopaminergic neurons and control of goal-directed behaviors. Trends Neurosci. 2007;30:220-7.

63. Yavas E, Young AMJ. N-Methyl-d-aspartate modulation of nucleus accumbens dopamine release by metabotropic glutamate receptors: fast cyclic voltammetry studies in rat brain slices in vitro. ACS Chem Neurosci. 2017:8:320-8.

64. Sinkala E, McCutcheon JE, Schuck MJ, Schmidt E, Roitman MF, Eddington DT. Electrode calibration with a microfluidic flow cell for fast-scan cyclic voltammetry. Lab Chip. 2012;12:2403-8. 
65. Goto Y, Grace AA. Limbic and cortical information processing in the nucleus accumbens. Trends Neurosci. 2008;31:552-8.

66. Schultz W. Multiple dopamine functions at different time courses. Annu Rev Neurosci. 2007;30:259-88

67. Rothwell NJ, Stock MJ, Tyzbir RS. Mechanisms of thermogenesis induced by low protein diets. Metab Clin Exp. 1983;32:257-61.

68. Day JJ, Roitman MF, Wightman RM, Carelli RM. Associative learning mediates dynamic shifts in dopamine signaling in the nucleus accumbens. Nat Neurosci. 2007;10:1020-8.

69. Rice ME, Patel JC, Cragg SJ. Dopamine release in the basal ganglia. Neuroscience. 2011;198:112-37.

70. Tellez LA, Han W, Zhang X, Ferreira TL, Perez IO, Shammah-Lagnado SJ, et al. Separate circuitries encode the hedonic and nutritional values of sugar. Nat Neurosci. 2016;19:465-70.

71. Matthews M, Bondi C, Torres G, Moghaddam B. Reduced presynaptic dopamine activity in adolescent dorsal striatum. Neuropsychopharmacology. 2013;38:1344-51.

72. Pitts EG, Stowe TA, Christensen B, Ferris MJ. Comparing dopamine release, uptake, and D2 autoreceptor function across the ventromedial to dorsolateral striatum in adolescent and adult rats. Neuropharmacology. 2020;175:108163.

73. Coulter CL, Happe HK, Murrin LC. Postnatal development of the dopamine transporter: a quantitative autoradiographic study. Brain Res Dev Brain Res. 1996;92:172-81.

74. Lieberman OJ, McGuirt AF, Mosharov EV, Pigulevskiy I, Hobson BD, Choi S, et al. Dopamine triggers the maturation of striatal spiny projection neuron excitability during a critical period. Neuron. 2018;99:540-.e4.

75. Brenhouse HC, Sonntag KC, Andersen SL. Transient D1 dopamine receptor expression on prefrontal cortex projection neurons: relationship to enhanced motivational salience of drug cues in adolescence. J Neurosci. 2008;28:2375-82.

76. Doura MB, Gold AB, Keller AB, Perry $D C$. Adult and periadolescent rats differ in expression of nicotinic cholinergic receptor subtypes and in the response of these subtypes to chronic nicotine exposure. Brain Res. 2008;1215:40-52.
77. Labouèbe G, Liu S, Dias C, Zou H, Wong JCY, Karunakaran S, et al. Insulin induces long-term depression of ventral tegmental area dopamine neurons via endocannabinoids. Nat Neurosci. 2013;16:300-8.

78. Liu S, Borgland SL. Insulin actions in the mesolimbic dopamine system. Exp Neurol. 2019;320:113006.

79. Fontana L, Cummings NE, Arriola Apelo SI, Neuman JC, Kasza I, Schmidt BA, et al. Decreased consumption of branched-chain amino acids improves metabolic health. Cell Rep. 2016;16:520-30.

80. Kenny PJ. Common cellular and molecular mechanisms in obesity and drug addiction. Nat Rev Neurosci. 2011;12:638-51.

81. Naef L, Pitman KA, Borgland SL. Mesolimbic dopamine and its neuromodulators in obesity and binge eating. CNS Spectr. 2015;20:574-83.

82. Paus T, Keshavan M, Giedd JN. Why do many psychiatric disorders emerge during adolescence? Nat Rev Neurosci. 2008;9:947-57.

83. Paxinos G, Watson C. The rat brain in stereotaxic coordinates. 6th ed. New York: Academic Press; 2007.

(i) Open Access This article is licensed under a Creative Commons Attribution 4.0 International License, which permits use, sharing, adaptation, distribution and reproduction in any medium or format, as long as you give appropriate credit to the original author(s) and the source, provide a link to the Creative Commons license, and indicate if changes were made. The images or other third party material in this article are included in the article's Creative Commons license, unless indicated otherwise in a credit line to the material. If material is not included in the article's Creative Commons license and your intended use is not permitted by statutory regulation or exceeds the permitted use, you will need to obtain permission directly from the copyright holder. To view a copy of this license, visit http://creativecommons. org/licenses/by/4.0/.

(c) The Author(s) 2020 